\title{
Temporal Pattern of C1q Deposition After Transient Focal Cerebral Ischemia
}

\author{
William J. Mack, ${ }^{1 \star}$ Michael E. Sughrue, ${ }^{1}$ Andrew F. Ducruet, ${ }^{1}$ J Mocco, ${ }^{1}$ \\ Sergey A. Sosunov, ${ }^{1}$ Benjamin G. Hassid, ${ }^{1}$ Joshua Z. Silverberg, ${ }^{1}$ Vadim S. Ten, ${ }^{2}$ \\ David J. Pinsky, ${ }^{3}$ and E. Sander Connolly Jr. ${ }^{1}$ \\ ${ }^{1}$ Department of Neurological Surgery, College of Physicians \& Surgeons, Columbia University, \\ New York, New York \\ ${ }^{2}$ Department of Pediatrics, College of Physicians \& Surgeons, Columbia University, \\ New York, New York \\ ${ }^{3}$ Division of Cardiology, Department of Medicine, University of Michigan, Ann Arbor, Michigan
}

Recent studies have focused on elucidating the contribution of individual complement proteins to post-ischemic cellular injury. As the timing of complement activation and deposition after cerebral ischemia is not well understood, our study investigates the temporal pattern of $\mathrm{C} 1 \mathrm{q}$ accumulation after experimental murine stroke. Brains were harvested from mice subjected to transient focal cerebral ischemia at $3,6,12$, and $24 \mathrm{hr}$ post reperfusion. Western blotting and light microscopy were employed to determine the temporal course of $\mathrm{C} 1 \mathrm{q}$ protein accumulation and correlate this sequence with infarct evolution observed with TTC staining. Confocal microscopy was utilized to further characterize the cellular localization and characteristics of $\mathrm{C} 1 \mathrm{q}$ deposition. Western Blot analysis showed that $\mathrm{C} 1 \mathrm{q}$ protein begins to accumulate in the ischemic hemisphere between 3 and $6 \mathrm{hr}$ post-ischemia. Light microscopy confirmed these findings, showing concurrent $\mathrm{C} 1 \mathrm{q}$ protein staining of neurons. Confocal microscopy demonstrated colocalization of $\mathrm{C} 1 \mathrm{q}$ protein with neuronal cell bodies as well as necrotic cellular debris. These experiments demonstrate the accumulation of C1q protein on neurons during the period of greatest infarct evolution. This data provides information regarding the optimal time window during which a potentially neuroprotective antiC1q strategy is most likely to achieve therapeutic success. ๑ 2006 Wiley-Liss, Inc.

Key words: cerebral ischemia; mouse; complement; C1q; neuroprotection; reperfusion injury

Significant effort has been dedicated to the identification of inflammatory mediators whose inhibition can reduce the extent of brain damage after occlusion of a major cerebral artery (Fagan et al., 2005). Many such efforts have focused on modulating the complement cascade, which has been implicated in a wide variety of pathologic processes (D'Ambrosio et al., 2001). Tissue subjected to ischemia and reperfusion activates complement (Vakeva et al., 1994; Collard et al., 1997; Vakeva et al., 1998; Zhou et al., 2000; D’Ambrosio et al., 2001;
Wada et al., 2001). In stroke, this process may lead to the expansion of the ischemic core into otherwise viable penumbral tissue (D'Ambrosio et al., 2001).

The complement cascade incorporates the classical, alternative, and mannose pathways. The classical arm is initiated by the deposition of $\mathrm{C} 1$ onto the surface of target cells. C1 is a three-protein complex consisting of C1q, C1r, and C1s. The largest of these proteins, C1q, has the unique property of having its own specific receptors and cellular functions, in addition to its ability to participate in the formation of a C3-convertase (Tenner, 2001). Thus, cellular deposition of $\mathrm{C} 1 \mathrm{q}$ has the potential to cause tissue injury via a broad array of complement cascade-dependent and independent mechanisms (Tenner, 2001). The precise inciting molecular event is not entirely clear. Work by Rossen and $\mathrm{CO}^{-}$ workers suggested that loss of membrane integrity, causing exposure of sub-cellular components to the extracellular milieu, attracts $\mathrm{C} 1 \mathrm{q}$, leading to activation of the downstream effectors of complement (Rossen, 1988; Kagiyama, 1989). The resulting pro-inflammatory mediators are believed to cause inflammation and tissue injury in sites remote from the initially injured cells (Chakraborti et al., 2000; Gasque et al., 2000).

Recent anti-ischemic strategies have focused on the classical complement pathway and its downstream influence on inflammation and reperfusion injury. Our group found that mice treated with the complement inhibitor soluble complement receptor-1 (sCR1) experience a modest reduction in cerebral infarct volume and im-

Contract grant sponsor: National Institutes of Health; Contract grant number: RO1 NS40409.

^Correspondence to: William J. Mack, MD, Dept. of Neurological Surgery, Columbia University, 710 West 168th Street, New York, NY 10032. E-mail: wjm32@columbia.edu

Received 19 August 2005; Revised 17 November 2005; Accepted 7 December 2005

Published online 30 January 2006 in Wiley InterScience (www. interscience.wiley.com). DOI: 10.1002/jnr.20775 
provement in neurologic outcome after middle cerebral artery occlusion (MCAO), presumably in large part through blockade of the downstream effects of post-ischemic cerebral C1q expression (Huang et al., 1999). Nevertheless these studies did not definitively confirm the time course of this upregulation. Gaining insight into the temporal sequence of events in cerebral ischemia is critically important for targeting potential treatments, as many stroke therapies seem to have a narrow therapeutic window. This in turn may explain the failure of several clinical trials (Gladstone et al., 2002). As the timing of complement activation after stroke is not well understood, this study investigates the temporal pattern of $\mathrm{C} 1 \mathrm{q}$ accumulation and deposition after experimental murine stroke, and places this in context of infarct evolution.

\section{MATERIALS AND METHODS}

\section{Antibodies and Reagents}

Primary antibodies and reagents used included antiMicrotubule Associated Protein (MAP-2) (Chemicon, Temecula, CA), anti-C1q (Connex GmbH, Martinsried, Germany) (used for immunohistochemistry), anti-C1q (Quidel Corporation, San Diego, CA) (used for Western blot), and Neurotrace 640/660 Fluorescent Nissl (Molecular Probes, Eugene, OR). Secondary antibodies were biotinylated anti-IgG) (Jackson ImmunoResearch Laboratories, West Grove, PA), Alexa Fluor488, 594, or 639 conjugated anti-IgG (Molecular Probes) and horseradish peroxidase-conjugated anti-IgG (Jackson ImmunoResearch Laboratories).

\section{Mice}

All experiments were conducted in a humane manner in accordance with the guidelines published in the $\mathrm{NIH}$ Guide for the Care and Use of Laboratory Animals, and under the supervision and approval of the Columbia University Institutional Animal Care and Use Committee. We utilized adult male C57BL/6 mice, age 8-10 weeks, weighing between 22 and $26 \mathrm{~g}$ at the time of surgery. Mice were housed in certified animal care barrier facilities in micro isolator cages with free access to food and water on a 12-hr light/ dark cycle.

\section{Murine Model of Focal Cerebral Ischemia}

These studies utilized the intraluminal filament model described previously, with minor modifications (Connolly et al., 1996). Briefly, mice were anesthetized, intubated, and maintained under general inhaled anesthesia on a mechanical ventilator, with settings demonstrated by serial arterial blood gasses to maintain normoxia and normocapnia. Middle cerebral artery occlusion was carried out by advancing a heatblunted, silicon-coated 7-0 nylon suture via the external carotid artery to the origin of the middle cerebral artery. After $60 \mathrm{~min}$ of ischemia, the occluding suture was withdrawn to establish reperfusion. Mice subjected to sham surgery underwent an identical operative procedure, without insertion of the occluding suture.

Transcranial measurements of cerebral blood flow (CBF) were made using laser-Doppler flowmetry (Periflux System
5000, Perimed, Inc., North Royalton, OH) as described previously (Connolly et al., 1996), using $0.5 \mathrm{~mm}$ flexible fiberoptic Doppler probes (Perimed) attached with tissue adhesive to the intact skull over landmarks published previously $(2 \mathrm{~mm}$ posterior to the bregma, $6 \mathrm{~mm}$ to each side of midline). Relative CBF measurements were made after anesthesia, immediately after occlusion, before reperfusion, and immediately after reperfusion to confirm proper suture placement and adequate reperfusion. Strict criteria are utilized to prospectively exclude animals that do not experience significant CBF drop-off $(>70 \%$ of baseline), do not maintain consistent levels of CBF decrease or do not demonstrate adequate reperfusion ( $>90 \%$ of baseline).

At specified, randomized time points $(3,6,12$, or $24 \mathrm{hr}$ after MCAO), mice were sacrificed, and their brains were perfused by transcardiac injection of ice cold PBS and removed intact. Sham mice were sacrificed $24 \mathrm{hr}$ post-operatively. Normal non-operative mice served as uninjured controls.

\section{Western Blot}

Mice underwent the focal cerebral ischemia procedure described above, or sham surgery, and were sacrificed after 3 , 6,12 , or $24 \mathrm{hr}$ ( $n=1$ per time point). The brains were saline perfused, rapidly harvested in one piece, divided into ipsilateral (injured) and contralateral (uninjured) hemispheres, and snapfrozen in liquid nitrogen. Samples were suspended in PBS, homogenized using a motorized glass-Teflon Potter homogenizer in the presence of protease inhibitor cocktail tablet (Roche, Basel, Switzerland), and centrifuged at $800-1,000 \times g$ for $10 \mathrm{~min}$. The supernatant was then spun at $15,000 \times g$ to pellet out cellular debris. Total protein concentration was evaluated with BCA assay (Pierce Chemical, Rockford, IL), and samples were diluted to a total protein concentration of $1-5 \mu \mathrm{g} / \mu \mathrm{l}$.

Fifty $\mu \mathrm{g}$ of total protein per sample were denatured in SDS with reducing agent, and run on NuPAGE Novex 4$12 \%$ Bis-Tris Gel (Invitrogen, Carlsbad, CA) under reducing conditions. Protein was transferred to a nitrocellulose membrane using $30 \mathrm{~V}$ current applied for $60 \mathrm{~min}$. Membranes were first stained to determine total protein content using Ponceau S stain $(0.5 \%$ Ponceau S, $1.0 \%$ glacial acetic acid, in de-ionized water), followed by imaging using a digital scanner. After imaging, blots were destained by washing in Tween-Tris buffered saline (TTBS) $(0.1 \%$ Tween-20 in $100 \mathrm{mM}$ Tris-CL $[\mathrm{pH} 7.5], 0.9 \% \mathrm{NaCl}$ ) for $5 \mathrm{~min}$, and were then washed briefly with $0.1 \mathrm{M}$ tris buffered saline (TBS), and blocked for $1 \mathrm{hr}$ in $0.1 \mathrm{M}$ TBS containing 5\% non-fat dry milk at room temperature with constant agitation. Membranes were then incubated with the primary antibody (anti-C1q antibody) in TBS with $0.05 \%$ Tween-20 (TBST) in 2\% nonfat dry milk for $3 \mathrm{hr}$, and then washed three times for $5 \mathrm{~min}$ each in TBST. After washing, membranes were incubated with horseradish peroxidaseconjugated rabbit anti-goat secondary antibody for $30 \mathrm{~min}$ and then washed three times for $5 \mathrm{~min}$ in TBST, and twice in TBS. Immunoreactive bands were then detected using a chemiluminescence kit (Roche), and membranes exposed to X-ray film (Eastman Kodak, Rochester, NY). Protein loading was assessed by probing the blot for beta actin, with densitometry indicating no significant differences in loading between the various lanes. 


\section{Immunohistochemistry}

Mice underwent the focal cerebral ischemia procedure described above and were sacrificed after 3,6 , or $24 \mathrm{hr}(n=3$ per time point). The brains were saline perfused, rapidly harvested in one piece, and fixed in 4\% paraformaldehyde for $12 \mathrm{hr}$ at $4{ }^{\circ} \mathrm{C}$. Brains were then incubated in $15 \%$ sucrose for $1 \mathrm{hr}$, followed by overnight incubation in 30\% sucrose. Next, brains were frozen in optimal cutting temperature (OCT) compound on dry ice then placed at $-80^{\circ} \mathrm{C}$. Coronal sections $(10 \mu \mathrm{m})$ were cut using a cryostat and washed twice in ice cold PBS.

For light microscopy, sections were incubated in $0.3 \%$ peroxidase in $70 \%$ methanol for $30 \mathrm{~min}$. Sections $(10 \mu \mathrm{m})$ were then blocked with the secondary antibody appropriate serum $(10 \%$ donkey or goat serum) with $0.2 \%$ Triton X-100 for $90 \mathrm{~min}$ at room temperature, followed by biotin blocking using a commercial kit. Primary antibodies were diluted in PBS with 5\% normal serum, 0.3\% Triton X-100. The tissue was blocked in $10 \%$ donkey serum, followed by incubation with the primary antibody for $90 \mathrm{~min}$ at room temperature. Sections were washed and incubated with the biotinylated secondary antibodies for $1 \mathrm{hr}$, followed by incubation with peroxidase linked avidin-biotin complex (Elite ABC kit, Vector Laboratories, Burlingame, CA) for $1 \mathrm{hr}$. The reaction product was visualized with diaminobenzidine and hydrogen peroxide. Slides were then mounted and visualized by an observer blinded to the recovery duration.

For immunofluorescence staining, $10-\mu \mathrm{m}$ sections were blocked with the secondary antibody appropriate serum $(10 \%$ donkey or goat serum) with $0.2 \%$ Triton X-100 for $1.5 \mathrm{hr}$ at room temperature. Primary antibodies were diluted in PBS with 5\% normal serum containing $0.3 \%$ Triton X-100. The tissue was blocked in $10 \%$ donkey serum, followed by incubation with the primary antibody for $90 \mathrm{~min}$ at room temperature. Sections were washed and incubated with fluorochromeconjugated secondary antibodies for $1 \mathrm{hr}$. Nissl staining $(20 \mathrm{~min}$, room temperature) was used for counterstaining. Sections were then mounted on slides in Vectashield (Vector Laboratories) and visualized using a Bio-Rad 2000 confocal laser-scanning device attached to a Nikon E800 microscope.

Semi-quantitative analysis of the immunohistochemical images was carried out to quantify the total amount of complement immunostaining in the infarct. Images were captured under identical fluorescence and magnification settings. Multiple (typically 10-15 images/slide) non-overlapping medium power fields $(40 \times$ objective with $1 \times$ zoom) were imaged to cover the entire infarct area. Images were captured and saved in TIFF format to maintain data quality. Adobe Photoshop v5.5 was then used to split the RGB channels, and the contrast and brightness for the green and blue channels were both set to -100 . These modified channels were then merged leaving only the red channel contribution to the image (representing complement component staining). These modified images were then converted to 8-bit gray scale, and analyzed using Image Pro Plus 4.5 (Media Cybernetics, Silver Spring, MD) software. The percentage area occupied by positive immunostaining was calculated for each image and the mean value for each animal was determined by averaging values from all images taken from that animal. Because of the use of medium power fields, values for amount of immunostaining calculated using this method typically range from $0-2.5 \%$ of the field covered, depending on antibody and reagent characteristics. Data presented represent an average of the mean values for each animal.

Several controls were used to confirm the validity of complement staining. Primary antibody specificity was confirmed by visualizing both unstained infarcted tissue from C57Bl/6 wild-type mice and wild-type tissue incubated with secondary antibodies without primary antibodies using confocal microscopy. To further confirm complement antibody specificity, infarcted tissue from C57Bl/6 wild-type mice stained with primary antibodies was blocked with purified Human C1q protein (Quidel Corp, San Diego, CA). Peptide blocking abolished complement antibody staining (not shown). Infarcted brains from C1qa $(-/-)$ knockout mice (Botto et al., 1998) were immunostained for C1q (not shown). The lack of immunostaining seen in these brains suggested that the complement staining in wild-type brains resulted from in vivo complement deposition, as opposed to artefactual deposition of complement in necrotic brain tissue from the blocking serum.

One millimeter sections utilized for triphenyltetrazolium chloride (TTC) staining were immersed in 2\% TTC in $0.9 \%$ saline and incubated for $25 \mathrm{~min}$ at $37^{\circ} \mathrm{C}$. TTC stains of adjacent tissue sections were used to confirm infarct localization, and the entire ipsilateral and contralateral slices were visually searched for immunopositivity. For confocal microscopy, the necrotic core was further identified by the regional loss of MAP-2 immunopositivity, which has been demonstrated to be an early immunochemical marker of ischemic neuronal injury (Collard et al., 1997). Cells were identified as neurons based on morphology and size in light microscopy, and based on the presence of remnant MAP-2 immunopositivity surrounding Nissl stained nuclei in fluorescent microscopy.

\section{Statistical Analysis}

Between-group analyses of semi-quantitative immunostaining data at the various time points were carried out utilizing one-way analysis of variance (ANOVA). All values are expressed as means $\pm \mathrm{SE}$, with $P<0.05$ considered statistically significant.

\section{RESULTS}

\section{C1q Protein Begins to Accumulate in the Brain Between 3 and $6 \mathrm{hr}$ After Ischemic Injury}

Western blots of homogenated mouse brains probed with a polyclonal anti-C1q antibody yielded two prominent bands (Fig. 1). The lower molecular weight band, which is centered around $30 \mathrm{kD}$, has been wellcharacterized by others, and represents 3 closely clustered bands of the three $\mathrm{C} 1 \mathrm{q}$ sub-components (C1q- $\alpha$ [34 $\mathrm{kD}$ ], C1q- $\beta$ [32 kD], C1q- $\gamma$ [25 kD]) (Reid and Porter, 1976; Loos, 1983). The higher molecular weight band is located above the $60 \mathrm{kD}$ marker, and likely is produced by the closely clustered bands of unreduced $\alpha-\beta(65 \mathrm{kD})$ and $\gamma-\gamma(63 \mathrm{kD})$ dimers described by Loos (1983).

No visually or densitometrically apparent differences were observed in the intensity of bands at $30 \mathrm{kD}$ of the ipsilateral and contralateral hemispheres at any time 
point. In contrast, $\mathrm{C} 1 \mathrm{q}$ protein began to accumulate in the ipsilateral hemisphere of mice by $6 \mathrm{hr}$, as manifested by a marked increase in the intensity of the band near $60 \mathrm{kD}$, suggesting an accumulation of the unreduced protein dimers. This band was also prominent in the ipsilateral hemispheres of mice 12 and $24 \mathrm{hr}$ after onset of ischemia. This band was not seen in any homogenates from the contralateral hemispheres. Densitometric analysis of the beta-actin bands indicated that the total protein content of each lane did not differ.

\section{C1q Deposits in the Brain Parenchyma During a Period of Significant Infarct Evolution}

Consistent with the temporal pattern of C1q accumulation in ischemic brain tissue observed by western

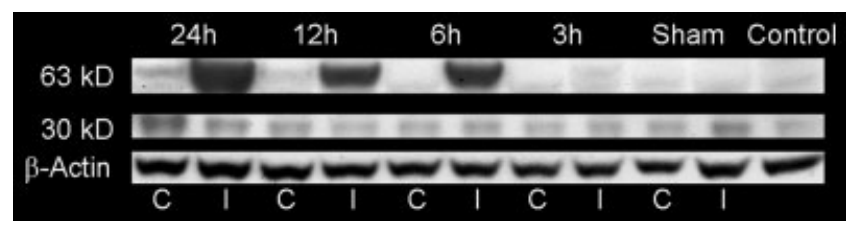

Fig. 1. Western blot of homogenated cerebral tissue from un-operated and sham-operated control mice, as well as mice sacrificed at 3, 6,12 , and $24 \mathrm{hr}$ after the onset of ischemia, probed with polyclonal anti-C1q antibody. The left and right lanes for each time point represent specimens taken from the contralateral (uninjured) and ipsilateral (injured) hemispheres respectively. The control lane consists of tissue taken from one hemisphere of an un-operated mouse. blot, evidence of cellular C1q deposition in the brain was absent at $3 \mathrm{hr}$ post-ischemia as detected by light microscopy (Fig. 2D). At $6 \mathrm{hr}$ post-injury, however, C1q immunopositive cells resembling neurons were detected throughout much of the infarct area (Fig. 2E). By 24 hr, C1q deposition was more widespread; however the greatest increase in $\mathrm{C} 1 \mathrm{q}$ positively staining structures occurred between 3 and 6 hr (Fig. 2F).

TTC staining of mouse brains at $3 \mathrm{hr}$ after MCAO showed a limited extent of cerebral infarction, which incompletely involved portions of the striatum and neocortex, and was mainly located in the middle coronal sections through the striatum and rostral thalamus, which in this model are destined to have the most extensive infarcts (Fig. 2A). By $6 \mathrm{hr}$, the cerebral infarct was far more extensive, and had more uniformly involved these central regions, with only a slight interval increase in infarct extent observed between 6 and $24 \mathrm{hr}$ (Fig. 2B,C).

\section{C1q is Found on Neurons and Neuronal Remnants After 6 hr}

Similar to the pattern observed using light microscopy, immunofluorescent staining for $\mathrm{C} 1 \mathrm{q}$ in brains of wild-type mice at 6 and $24 \mathrm{hr}$ post-ischemia showed widespread staining for components in the infarcted region of the ipsilateral cortex, that was largely not seen at $3 \mathrm{hr}$ (Fig. 3A-I). C1q was frequently found to colocalize with microtubule associated protein (MAP-2) on cells in the infarcted cortex, implying that complement

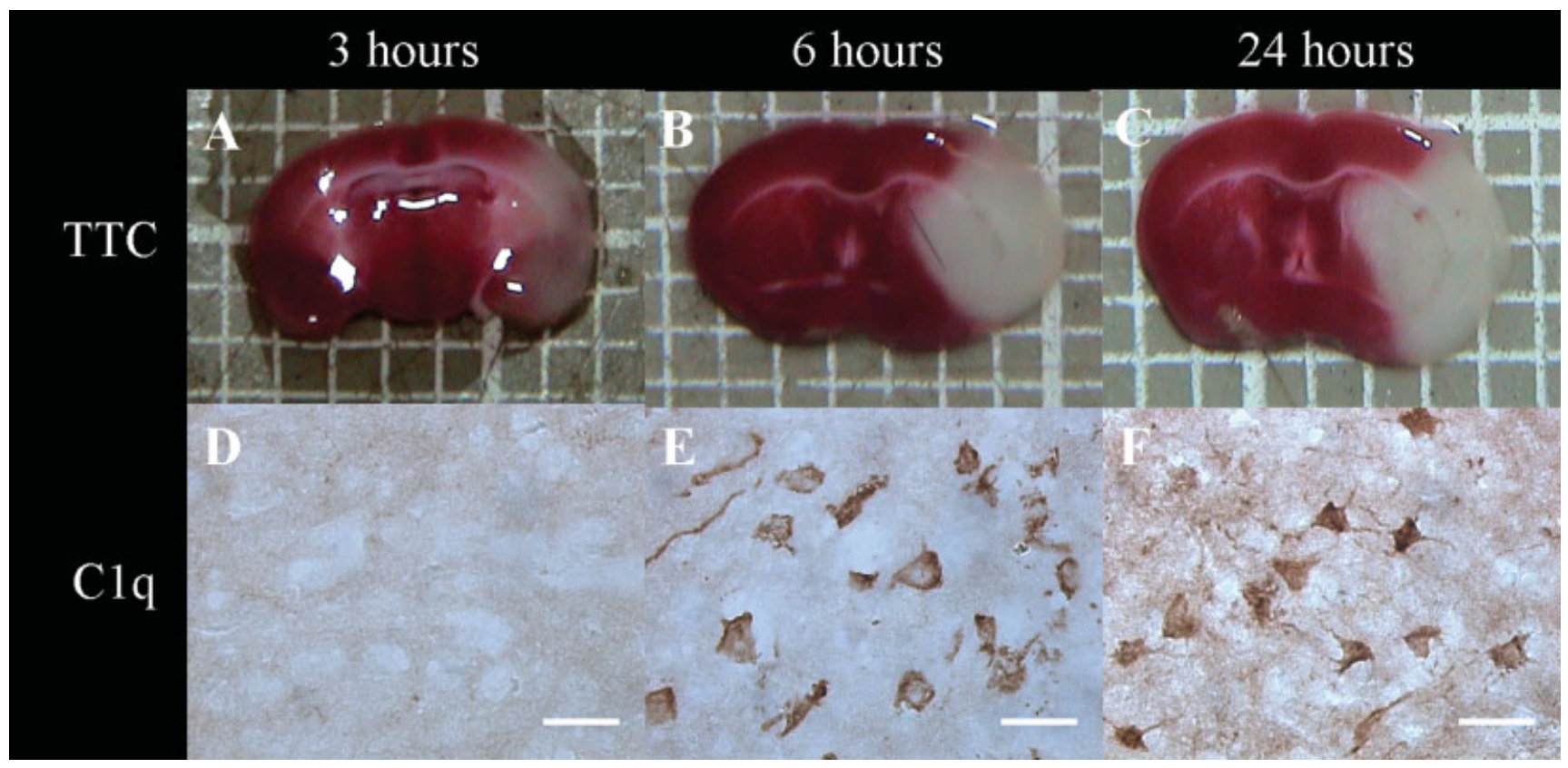

Fig. 2. Temporal pattern of $\mathrm{C} 1 \mathrm{q}$ deposition and the relation to infarct evolution. Immunohistochemical time course demonstrating temporal pattern of complement component C1q deposition in the ipsilateral neocortex at 3, 6, and $24 \mathrm{hr}$ after ischemic injury, using light (D-F) microscopy. Representative coronal slices through the center portion of the MCA territory stained with TTC are provided for comparison $(\mathbf{A}-\mathbf{C})$. C1q deposition was not found in any observed sections at $3 \mathrm{hr}$ post-ischemia. Subsequent neuronal deposition of both proteins was routinely found at $6 \mathrm{hr}$, and became widespread throughout the infarct by $24 \mathrm{hr}$. A significant interval expansion of the infarct was found to occur between these time points as well. Scale bar $=30 \mu \mathrm{m}$. 
Fig. 3. Immunofluorescence imaging for C1q. Confocal images taken from infarcted neocortex depict colocalization of C1q with neuronal processes, as well as necrotic cellular debris. Images are derived from sections harvested at $3 \mathrm{hr}(\mathbf{A}$, $\mathbf{D}, \mathbf{G}), 6 \mathrm{hr}(\mathbf{B}, \mathbf{E}, \mathbf{H})$, and $24 \mathrm{hr}(\mathbf{C}, \mathbf{F}$, I) post-reperfusion. Nissl staining is represented in blue, MAP-2 staining is represented in green, and $\mathrm{C} 1 \mathrm{q}$ is stained in red, colocalized cells stain yellow. The channels have been split to clarify the colocalization. Scale bar $=30 \mu \mathrm{m}$.

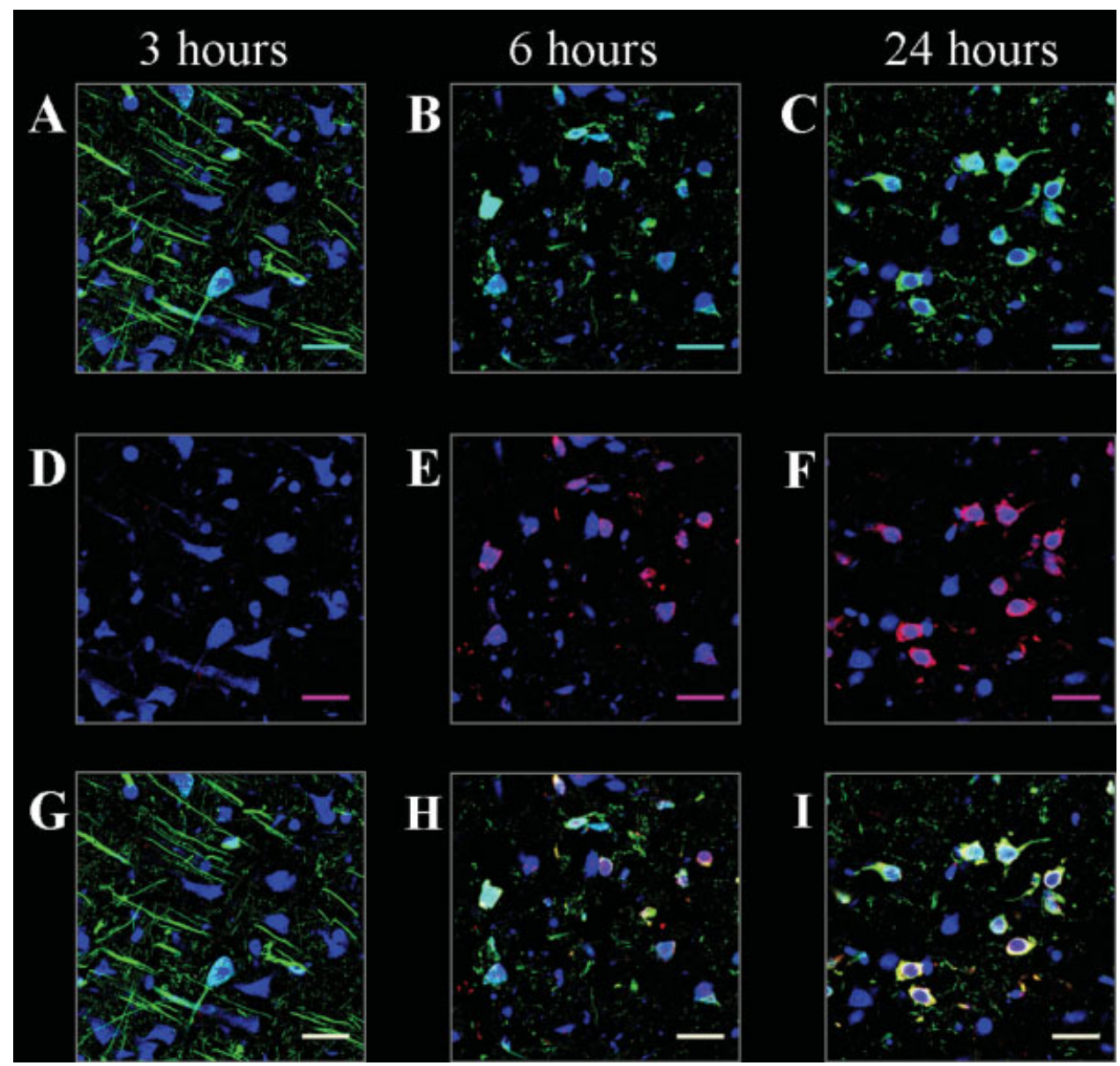

accumulation occurs in neurons. Some complement immunostaining was identified on diffuse material that likely represents necrotic cellular debris. Semi-quantitative analysis of this immunofluorescence showed a difference in immunopositivity between the three groups (3 hr: $0.0397 \pm 0.0154,6 \mathrm{hr}: 0.458 \pm 0.105,24 \mathrm{hr}:$ $0.497 \pm 0.142$; ANOVA $P=0.05$ ) (Fig. 4).

\section{DISCUSSION}

Western blot analysis demonstrates that $\mathrm{C} 1 \mathrm{q}$ begins to accumulate in the brains of mice between 3 and $6 \mathrm{hr}$ after the onset of cerebral ischemia. This corresponds temporally to an interval increase in neuronal C1q deposition as evidenced by immunohistochemistry, and was confirmed by semi-quantitative analysis of $\mathrm{Clq}$ immunofluorescence. Post-ischemic neuronal C1q accumulation after $24 \mathrm{hr}$ of reperfusion has been noted in prior investigations in both global and focal ischemia models (Huang et al., 1999; Schafer et al., 2000). This report represents the first characterization of complement deposition at early time points ( 3 and $6 \mathrm{hr}$ ) after focal reperfused stroke. Similar investigations in other tissues, such as myocardium and intestine, have showed complement immunopositivity somewhat earlier than $3 \mathrm{hr}$ post-ischemia (Vakeva et al., 1998; Zhao et al., 2002). The reason for this minor varia- tion is not clear, but may reflect differences in the experimental models or physiologic differences in complement upregulation between organ systems.

Of note, post-ischemic cerebral C1q deposition correlates temporally with the period of greatest infarct evolution as assessed by TTC staining. Determining the cause and effect in this sequence is difficult. Given the observation that $\mathrm{C} 1 \mathrm{q}$ deposition in ischemic myocardium likely results from a loss of membrane integrity and exposure of sub-cellular components (Rossen, 1988), neuronal C1q deposition may well result from a process of expanding cell death.

Interestingly, the observed onset of complement deposition coincides temporally with the period of blood-brain barrier breakdown reported in other studies (Belayev et al., 1996). The cell-specific origin of postischemic complement synthesis that leads to $\mathrm{C} 1 \mathrm{q}$ accumulation in the brain is not known. Whereas the liver is thought to be principally responsible for complement synthesis, it has been discovered recently that numerous extrahepatic cells are capable of complement production (Morgan and Gasque, 1996, 1997). Various brain cells, including neurons and glia, produce mRNA for the entire complement cascade in vitro (Gasque et al., 1992, 1993; van Beek et al., 2003). Furthermore, diverse forms 


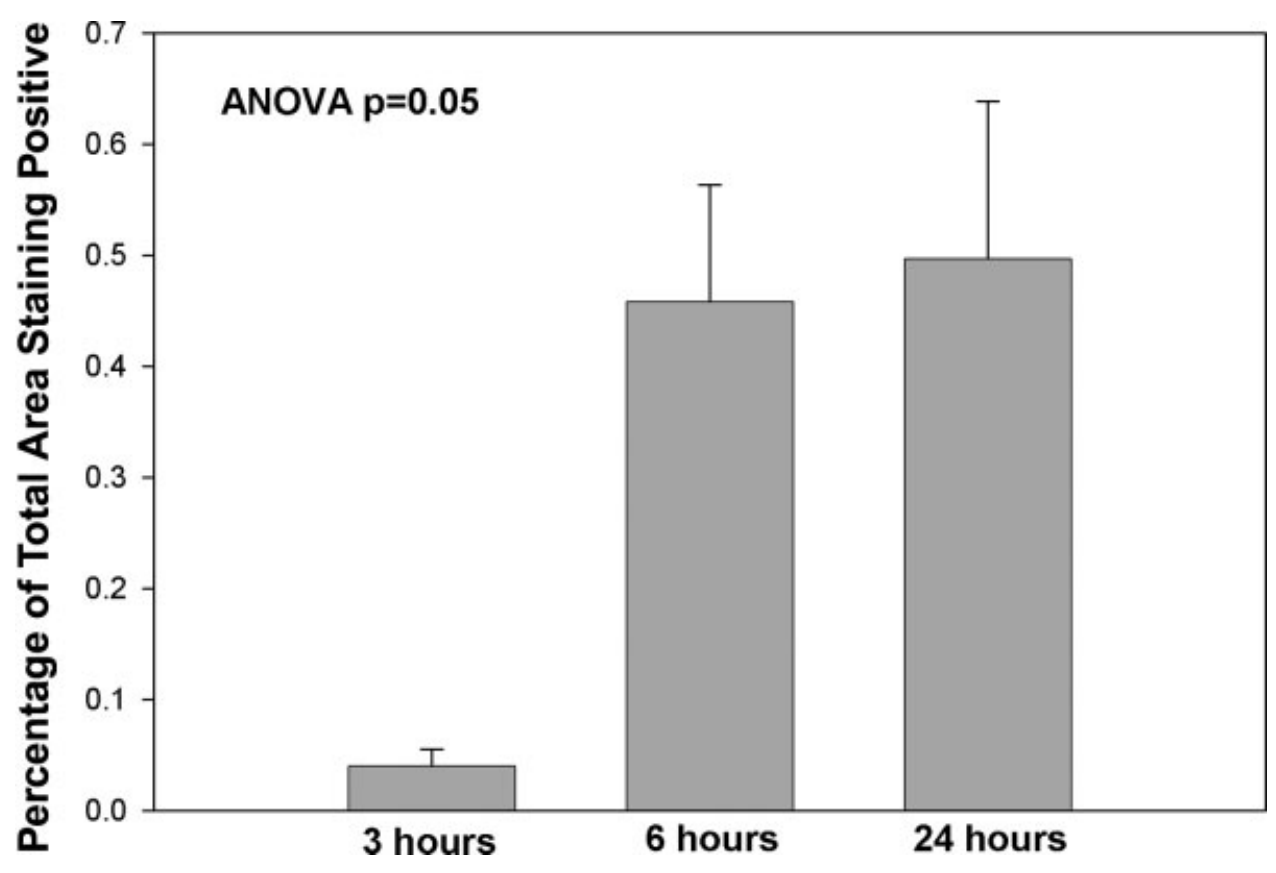

Fig. 4. Semi-quantitative Analysis of $\mathrm{C} 1 \mathrm{q}$ immunofluorescence. The mean percentage area occupied by $\mathrm{C} 1 \mathrm{q}$ immunostaining in the brains of wild-type mice subjected to ischemia/reperfusion and sacrificed at 3, 6, and $24 \mathrm{hr}$. Analysis was carried out on non-overlapping consecutive medium-powered fields for the full extent of anatomically equivalent representative slices for each animal, and these values were averaged to determine a per-animal average. Data presented represent the grouped per-animal averages. One-way analysis of variance carried out for between-group comparisons showed a $P$-value of 0.05 . of acute brain injury, including cerebral ischemia, seem to upregulate complement proteins, notably $\mathrm{C} 1 \mathrm{q}$, as demonstrated by an investigation that demonstrated microglial synthesis of C1q after transient global cerebral ischemia (Schafer et al., 2000). Given the large pool of available complement protein in the blood stream, it is likely that a significant portion of the cerebral C1q protein observed in our model between 3 and $6 \mathrm{hr}$ after ischemic onset enters with the loss of blood-brain barrier integrity (Belayev et al., 1996).

In summary, we present evidence that $\mathrm{C} 1 \mathrm{q}$ accumulates in the brain somewhat later than in other organ systems, and occurs during a period (3-6 hr post-ischemia) of rapid infarct evolution. These data provide information regarding the optimal time window during which a neuroprotective strategy targeting complement activation is most likely to achieve therapeutic success.

\section{ACKNOWLEDGMENTS}

Dr. Mocco was supported by the American Heart Association Heritage Affiliate Postdoctoral Research Fellowship. Dr. Mack was supported by the New York Academy of Medicine Glorney-Raisbeck Fellowship in Cardiovascular Diseases. We sincerely thank Dr. M. Botto (Imperial College, UK) for generously providing the C1qa $(-/-)$ mice.

\section{REFERENCES}

Belayev L, Busto R, Zhao W, Ginsberg MD. 1996. Quantitative evaluation of blood-brain barrier permeability following middle cerebral artery occlusion in rats. Brain Res 739:88-96.

Botto M, Dell'Agnola C, Bygrave AE, Thompson EM, Cook HT, Petry F, Loos M, Pandolfi PP, Walport MJ. 1998. Homozygous C1q deficiency causes glomerulonephritis associated with multiple apoptotic bodies. Nat Genet 19:56-59.

Chakraborti T, Mandal A, Mandal M, Das S, Chakraborti S. 2000. Complement activation in heart diseases. Role of oxidants. Cell Signal 12: 607-617.

Collard CD, Vakeva A, Bukusoglu C, Zund G, Sperati CJ, Colgan SP, Stahl GL. 1997. Reoxygenation of hypoxic human umbilical vein endothelial cells activates the classic complement pathway. Circulation 96: 326-333.

Connolly ES Jr, Winfree CJ, Stern DM, Solomon RA, Pinsky DJ. 1996. Procedural and strain-related variables significantly affect outcome in a murine model of focal cerebral ischemia. Neurosurgery 38:523-531; discussion 532 .

D'Ambrosio AL, Pinsky DJ, Connolly ES. 2001. The role of the complement cascade in ischemia/reperfusion injury: implications for neuroprotection. Mol Med 7:367-382

Fagan SC, Hess DC, Machado LS, Hohnadel EJ, Pollock DM, Ergul A. 2005. Tactics for vascular protection after acute ischemic stroke. Pharmacotherapy 25:387-395.

Gasque P, Dean YD, McGreal EP, VanBeek J, Morgan BP. 2000. Complement components of the innate immune system in health and disease in the CNS. Immunopharmacology 49:171-186.

Gasque P, Ischenko A, Legoedec J, Mauger C, Schouft MT, Fontaine M. 1993. Expression of the complement classical pathway by human glioma in culture. A model for complement expression by nerve cells. J Biol Chem 268:25068-25074.

Gasque P, Julen N, Ischenko AM, Picot C, Mauger C, Chauzy C, Ripoche J, Fontaine M. 1992. Expression of complement components of the alternative pathway by glioma cell lines. J Immunol 149:13811387.

Gladstone DJ, Black SE, Hakim AM. 2002. Toward wisdom from failure: lessons from neuroprotective stroke trials and new therapeutic directions. Stroke 33:2123-2136.

Huang J, Kim LJ, Mealey R, Marsh HC Jr, Zhang Y, Tenner AJ, Connolly ES Jr, Pinsky DJ. 1999. Neuronal protection in stroke by an sLex-glycosylated complement inhibitory protein. Science 285:595-599. 
Kagiyama A, Savage HE, Michael LH, Hanson G, Entman ML, Rossen RD 1989. Molecular basis of complement activation in ischemic myocardium: identification of specific molecules of mitochondrial origin that bind human C1q and fix complement. Circ Res 64:607-615.

Loos M. 1983. Biosynthesis of the collagen-like C1q molecule and its receptor functions for $\mathrm{Fc}_{\mathrm{c}}$ and polyanionic molecules on macrophages. Curr Top Microbiol Immunol 102:1-56.

Morgan BP, Gasque P. 1996. Expression of complement in the brain: role in health and disease. Immunol Today 17:461-466.

Morgan BP, Gasque P. 1997. Extrahepatic complement biosynthesis: where, when and why? Clin Exp Immunol 107:1-7.

Reid K, Porter RR. 1976. Subunit composition and structure of subcomponent $\mathrm{C} 1 \mathrm{q}$ of the first component of human complement. Biochem J 155:19-23.

Rossen R, Michael LH, Kagiyama A, Savage HE, Hanson G, Reisberg MA, Moake JN, Kim SH, Self D, Weakley S. 1988. Mechanism of complement activation after coronary artery occlusion: evidence that myocardial ischemia in dogs causes release of constituents of myocardial subcellular origin that complex with human C1q in vivo. Circ Res 62: 572-584.

Schafer MK, Schwaeble WJ, Post C, Salvati P, Calabresi M, Sim RB, Petry F, Loos M, Weihe E. 2000. Complement C1q is dramatically upregulated in brain microglia in response to transient global cerebral ischemia. J Immunol 164:5446-5452.
Tenner AJ. 2001. Complement in Alzheimer's disease: opportunities for modulating protective and pathogenic events. Neurobiol Aging 22: 849-861.

Vakeva A, Morgan BP, Tikkanen I, Helin K, Laurila P, Meri S. 1994. Time course of complement activation and inhibitor expression after ischemic injury of rat myocardium. Am J Pathol 144:13571368.

Vakeva AP, Agah A, Rollins SA, Matis LA, Li L, Stahl GL. 1998. Myocardial infarction and apoptosis after myocardial ischemia and reperfusion: role of the terminal complement components and inhibition by anti-C5 therapy. Circulation 97:2259-2267.

van Beek J, Elward K, Gasque P. 2003. Activation of complement in the central nervous system: roles in neurodegeneration and neuroprotection. Ann NY Acad Sci 992:56-71.

Wada K, Montalto MC, Stahl GL. 2001. Inhibition of complement C5 reduces local and remote organ injury after intestinal ischemia/reperfusion in the rat. Gastroenterology 120:126-133.

Zhao H, Montalto MC, Pfeiffer KJ, Hao L, Stahl GL. 2002. Murine model of gastrointestinal ischemia associated with complement-dependent injury. J Appl Physiol 93:338-345.

Zhou W, Farrar CA, Abe K, Pratt JR, Marsh JE, Wang Y, Stahl GL, Sacks SH. 2000. Predominant role for C5b-9 in renal ischemia/reperfusion injury. J Clin Invest 105:1363-1371. 